\title{
Sensitivity of Susceptibility-Weighted Imaging in Detecting Superparamagnetic Iron Oxide-Labeled Mesenchymal Stem Cells: A Comparative Study
}

\author{
Serah Park ${ }^{1}$; Byung Kook Kwak ${ }^{1,2} ;$; jisung Jung ${ }^{1}$ \\ ${ }^{1}$ Department of Radiology, Chung-Ang University College of Medicine, Seoul, Korea \\ 2 Department of Radiology, Chung-Ang University Hospital, Chung-Ang University College of Medicine, Seoul, Korea \\ *Corresponding author: Byung Kook Kwak, Department of Radiology, Chung-Ang University Hospital, Chung-Ang University College of Medicine, P. O. Box: 156-755, Seoul, Korea. Tel: \\ +82-262992661, Fax:+82-262631557, E-mail: kwakbk@cau.ac.kr
}

Received: June 3, 2014; Revised: September 3, 2014; Accepted: September 20, 2014

\begin{abstract}
Background: Susceptibility-weighted imaging (SWI) is extremely sensitive in the detection of superparamagnetic iron oxide (SPIO) nanoparticle-labeled cells. However, no study has compared molecular imaging for stem cell detection using SWI and other MRI pulse sequences.

Objectives: This study aims to assess the sensitivity of SWI in detecting SPIO nanoparticle-labeled, human bone marrow-derived mesenchymal stem cells (SPIO-hMSCs) compared with that of $\mathrm{T}_{2}$ - and $\mathrm{T}_{2}{ }^{*}$-weighted imaging $\left(\mathrm{T}_{2} \mathrm{WI}\right.$ and $\mathrm{T}_{2}{ }^{*} \mathrm{WI}$, respectively) in a phantom and in vivo study in rats.

Materials and Methods: A phantom was prepared with various cell concentrations. In one normal rat, SPIO-hMSCs were implanted directly through burr holes in to both caudate putamens, while in three rats without and six rats with photothrombotic infarction, $2.5 \times 10^{5} / \mathrm{ml}$ SPIO-hMSCs were infused into the ipsilateral internal carotid artery (ICA). $\mathrm{T}_{2} \mathrm{WI}, \mathrm{T}_{2}{ }_{2} \mathrm{WI}$, and SWI findings were compared for dark regions representing SPIO-hMSCs.

Results: SWI and $\mathrm{T}_{2}{ }^{*}$ WI detected $15 \mu \mathrm{L}$ of 13 SPIO-hMSCs $/ \mu \mathrm{L}$ and $15 \mu \mathrm{L}$ of 27 SPIO-hMSCs $/ \mu \mathrm{L}$ in the phantom, respectively and $3 \mu \mathrm{L}$ of 333 SPIO-hMSCs $/ \mu \mathrm{L}$ and $3 \mu \mathrm{L}$ of 167 SPIO-hMSCs/ $\mu \mathrm{L}$ in the normal rat brain (direct implantation). In the normal rat brain (ICA infusion), one of the three cases showed numerous foci of dark regions dispersed throughout the brain on $\mathrm{T}_{2}{ }^{*} \mathrm{WI}$ and SWI. Dark regions surrounded the infarcts in all six infracted rat brains. The dark region was most prominent on SWI, followed by $\mathrm{T}_{2}{ }^{*} \mathrm{WI}$ and $\mathrm{T}_{2} \mathrm{WI}$ in all six rats $(\mathrm{P}=0.002)$. Implanted SPIO-hMSCs were confirmed using Prussian blue staining.

Conclusions: SWI is the most sensitive in the detection of SPIO-hMSCs, with the dark regions representing SPIO-hMSCs being more prominent on SWI than on $\mathrm{T}_{2}{ }^{*} \mathrm{WI}$ and $\mathrm{T}_{2} \mathrm{WI}$.
\end{abstract}

Keywords: Mesenchymal Stromal Cells; Cerebral Infarction; Rats; Ferrosoferric Oxide

\section{Background}

Superparamagnetic iron oxide (SPIO) nanoparticles are used as contrast agents in $\mathrm{T}_{2}$-weighted magnetic resonance imaging (MRI) because of their ability to decrease the $\mathrm{T}_{2}$ relaxation time. Areas containing SPIO nanoparticles appear dark on $\mathrm{T}_{2}$-weighted imaging $\left(\mathrm{T}_{2} \mathrm{WI}\right)$ and $\mathrm{T}_{2}{ }^{*}$-weighted imaging $\left(\mathrm{T}_{2}{ }^{*} \mathrm{WI}\right)$ because SPIO nanoparticles decrease the signals originating from protons by fast proton dephasing, i.e. the susceptibility effect (1-3). Any SPIO nanoparticle-labeled cells can be tracked by MRI (4-8), which has the highest resolution among molecular imaging modalities. However, with respect to sensitivity in the detection of fewer cells, MRI is not superior to optical imaging. Therefore, cell detectability using MRI needs improvement, specifically by choosing the optimal pulse sequence. The most sensitive SPIO-labeled cell detection can be achieved by utilizing MRI pulse sequences that maximize its sensitivity to the susceptibility effect of SPIO nanoparticles, i.e. $\mathrm{T}_{2} \mathrm{WI}$ and $\mathrm{T}_{2}{ }^{*} \mathrm{WI}$ (9). Susceptibility-weighted imaging (SWI) is extremely sensitive to subtle changes and offers optimal detection for SPIO-labeled cell. It involves a three-dimensional (3D), fully flow-compensated, gradient-echo sequence with a long echo time (TE) $(10,11)$. However, till date, no study has compared molecular imaging for stem cell detection using SWI and that using other MRI pulse sequences (12).

\section{Objectives}

This study aimed to assess the sensitivity of SWI in the detection of SPIO nanoparticle-labeled, human bone marrow-derived mesenchymal stem cells (SPIO-hMSCs) compared with that of $\mathrm{T}_{2} \mathrm{WI}$ and $\mathrm{T}_{2}{ }^{*} \mathrm{WI}$ in a phantom and in vivo study.

Copyright (C) 2015, Tehran University of Medical Sciences and Iranian Society of Radiology. This is an open-access article distributed under the terms of the Creative Commons Attribution-NonCommercial 4.0 International License (http://creativecommons.org/licenses/by-nc/4.0/) which permits copy and redistribute the material just in noncommercial usages, provided the original work is properly cited. 
Park S et al.

\section{Materials and Methods}

\subsection{Cell Preparation and Labeling}

Mesenchymal stem cells derived from human bone marrow (hMSCs; Lonza, Walkersville, MD, USA) were grown in Dulbecco's modified Eagle's medium (DMEM) containing $10 \%$ fetal bovine serum, $200 \mathrm{mM}$ L-glutamine, and $0.1 \mathrm{mg} / \mathrm{mL}$ gentamicin (all Invitrogen, Carlsbad, CA, USA) at $37^{\circ} \mathrm{C}$ in $5 \% \mathrm{CO}_{2}$. Culture media were changed every 3-4 days, and the cells were subcultured at $80 \%-90 \%$ confluency. hMSCs labeling with SPIO nanoparticles was performed at approximately $80 \%$ confluency. To enable efficient internalization of SPIO nanoparticles into hMSCs, $1.5 \mu \mathrm{g} / \mathrm{mL}$ poly L-lysine hydrobromide (PLL; Sigma, St Louis, MO, USA) as the transfection agent and $100 \mu \mathrm{g}$ Fe/mL SPIO nanoparticles (Feridex IV; Advanced Susceptibility Inc., Cambridge, MA, USA) were combined in culture medium and gently shaken for $60 \mathrm{~min}$ at room temperature on a rotating shaker. hMSCs were supplied with culture media containing the SPIO-PLL complex at a final concentration of $50 \mu \mathrm{g} \mathrm{Fe} / \mathrm{mL}$ SPIO nanoparticles and $750 \mathrm{ng} / \mathrm{mL}$ PLL to ensure efficient labeling (6). The cell cultures were kept overnight at $37^{\circ} \mathrm{C}$ in $5 \% \mathrm{CO}_{2}$. Prussian blue staining was used to confirm successful and effective hMSC labeling. The cells labeled in 4-chamber slides (Lab-Tek; Electron Microscopy Science, Hatfield, PA, USA) were washed twice with phosphate-buffered saline (PBS) to remove excess unlabeled SPIO nanoparticles, fixed with 4\% paraformaldehyde for $30 \mathrm{~min}$, washed again, and incubated with $2 \%$ potassium ferrocyanide in $2 \%$ hydrochloric acid for $30 \mathrm{~min}$. After another PBS wash, the cells were counterstained with nuclear fast red. The SPIO labeling efficiency was microscopically observed.

\subsection{Cell Phantom}

SPIO-hMSCs were harvested by cell dissociation reagent (TrypLE Express, Invitrogen) treatment for $5 \mathrm{~min}$. SPIO-hMSCs were washed with the medium and centrifuged to obtain a 200 -cell $/ \mu \mathrm{L}$ concentration. To prepare cell phantoms of various concentrations, the cells were diluted to concentrations of $20,40,80,120,160$, and 200 cells $/ \mu \mathrm{L}$ in the medium. Furthermore, $2 \%$ agarose (Invitrogen) was prepared in distilled water. Five microliters of each cell concentration and $10 \mu \mathrm{L}$ of $2 \%$ agarose solution were mixed in a 1:2 ratio. Cell-agarose gel lumps were prepared. To prepare the phantom, 180 $\mu \mathrm{L}$ of $2 \%$ agarose solution was poured at the bottom of the 96-well plate, the lumps were placed in the center of the agarose gel, and $120 \mu \mathrm{L}$ of $2 \%$ agarose solution was added. Eight wells were linearly prepared, i.e. $15-\mu \mathrm{L}$ volume lumps of only $2 \%$ agarose; 7, 13, 27, 40, 53, and 67 SPIO-hMSCs $/ \mu \mathrm{L}$; and 67 unlabeled hMSCs $/ \mu \mathrm{L}$. Phantom preparation and MR imaging (the protocol will be mentioned later) were replicated five times.

\subsection{Animal Experiments}

The study protocol was approved by the institutional review board (CAUMD 11-0020), and the rats were maintained as per the Institutional Animal Ethics Committee at Chung-Ang University. Before the experiment, the rats were allowed to acclimatize for a week in a room under a 12-h light/dark cycle at $21-24{ }^{\circ} \mathrm{C}$ and were fed standard rat food and tap water ad libitum. Nine male Sprague Dawley rats (Daehan Biolink, Eumseong, Korea), each weighing 250-300 g, were used.

\subsection{Direct Implantation into Normal Rat Brains}

SPIO-hMSC cell suspensions at two cell concentrations, i.e. $3 \mu \mathrm{L}$ of 333 SPIO-hMSCs $/ \mu \mathrm{L}$ in serum-free medium for the right brain and $3 \mu \mathrm{L}$ of 167 SPIO-hMSCs $/ \mu \mathrm{L}$ for the left brain, were loaded into a Hamilton syringe (Hamilton Co, Reno, NV, USA) with a $25-\mathrm{G}$ needle. Three rats received intramuscular anesthesia with $50 \mathrm{mg} / \mathrm{kg}$ body weight Zoletil 50 (Virbac S.A, Carros, France) and $10 \mathrm{mg} /$ kg Rompun (Xylazine hydrochloride; Bayer Korea, Ansan, Korea). Rat heads were fixed in the stereotactic system (Stoelting, Wood Dale, IL, USA). The scalp skin was centrally incised and two burr holes were constructed on each side of the skull at $0.48 \mathrm{~mm}$ posterior to the bregma and $3.4 \mathrm{~mm}$ from the mid-line sagittal suture. The needle was inserted to a 6.4- $\mathrm{mm}$ depth into the caudate putamen using the stereotactic system. Cells were slowly injected into both caudate putamens for 3 min and the needle was kept in position for $10 \mathrm{~min}$. MRI (protocol will be mentioned later) was performed after an hour. The rats were sacrificed (protocol will be mentioned later) and their brains were harvested and fixed for histopathological studies.

\subsection{Internal Carotid Artery (ICA) Infusion in Nor- mal Rats and Rat Models with Cerebral Infarction}

SPIO-hMSCs were infused into the ICA of three normal rats and six rats with local brain infarction. To induce photothrombotic cerebral infarction (PTCI) (13, 14), the rats were anesthetized with $5 \%$ isoflurane (Aerane Solution, Ilsung, Seoul, South Korea) in $\mathrm{O}_{2}$ that was maintained with $1.5 \%-2 \%$ isoflurane. The rats were laid flat in the prone position with their heads fixed in the stereotactic system (Stoelting, Wood Dale, IL, USA). A midline scalp incision was placed and a fiberoptic cold light generator guide (Fiber-Lite MI-150; Dolan Jenner Co., Lancaster, SC, USA) with a 5-mm aperture was positioned on the skull, $2.5 \mathrm{~mm}$ right lateral to the midline and $2.5 \mathrm{~mm}$ posterior to the bregma. The wavelength of the light was $400-670 \mathrm{~nm}$, and its color temperature was $3200^{\circ} \mathrm{K}$. Following intravenous Rose Bengal $(20 \mathrm{mg} / \mathrm{kg}$; Sigma-Aldrich Co, St. Louis, MO, USA) injection through the tail vein, photoillumination was performed for 15 min, which generated free radicals from Rose Bengal, endothelial cell damage, platelet aggregation leading 
Park S et al.

to microvascular thrombosis, and eventually, vessel occlusion with circumscribed cortical infarction. The scalp was sutured with 4-0 blue-nylon and the rats were allowed to recover. During this procedure, the rectal temperature was monitored using the homeothermic blanket control unit (Harvard Apparatus, Holliston, MA, USA) and maintained between $36.5^{\circ} \mathrm{C}$ and $37^{\circ} \mathrm{C}$ with a feedback-controlled heating pad. Three days following photothrombotic infarction, SPIO-hMSCs were infused into the ipsilateral right ICA. Rats were anesthetized by intramuscular injection of $100 \mathrm{mg} / \mathrm{kg}$ body weight Ketara (Ketamine hydrochloride; Yuhan, Seoul, Korea) and $10 \mathrm{mg} / \mathrm{kg}$ Rompun (Xylazine hydrochloride; Bayer Korea, Ansan, Korea). The ipsilateral carotid artery was exposed and the external carotid artery was ligated with 6-0 silk, and $2.5 \times 10^{5}$ SPIO-hMSCs were injected into ICA through the common carotid artery using a $27-G$ needle (Introcan Certo; B Braun Melsungen AG, Melsungen, Germany). The common carotid artery was ligated with silk and the skin was closed. After $24 \mathrm{~h}$, MRI (protocol will be described later) was performed, following which the rats were sacrificed (protocol will be described later) and their brains harvested and fixed for histopathological study.

\subsection{Phantom MRI}

Using a 3.0-T clinical MRI scanner (Achieva; Philips Healthcare, Eindhoven, The Netherlands) and the SENSE-8 channel head coil (Philips Healthcare), $\mathrm{T}_{2} \mathrm{WI}$ (turbo spin echo; repetition time [TR] $818.7 \mathrm{~ms}$; TE, 80 $\mathrm{ms}$; flip angle, $90^{\circ} \mathrm{C}$; field of view, $180 \times 180 \mathrm{~mm}$; matrix size, $504 \times 445$, two-dimensional [2D] thickness, $1 \mathrm{~mm}$; 8 excitations; resolution, $0.36 \times 0.4 \times 1.0 \mathrm{~mm}$ ), T2*WI (gradient echo; TR, $262.4 \mathrm{~ms}$; TE, $9.2 \mathrm{~ms}$; flip angle, $30^{\circ} \mathrm{C}$; field of view, $180 \times 180 \mathrm{~mm}$; matrix size, $488 \times 485 ; 2 \mathrm{D}$; thickness, $1 \mathrm{~mm} ; 8$ excitations; resolution, $0.37 \times 0.37 \times$ $1.0 \mathrm{~mm}$ ), and SWI (TR, $33.1 \mathrm{~ms}$; TE, $43.1 \mathrm{~ms}$; flip angle, $10^{\circ}$; field of view, $180 \times 180 \mathrm{~mm}$; matrix size, $344 \times 350$; 3D; thickness, $1 \mathrm{~mm} ; 8$ excitations; resolution, $0.52 \times 0.51 \times$ $0.5 \mathrm{~mm}$ ) were performed. A radiologist (B.K.K, one of the authors) with 23 years of experience interpreted the images with respect to the detection and size of dark regions.

\subsection{In Vivo Rat Brain MRI}

In vivo rat brain MRI was performed using a 3.0-T clinical MRI scanner (Achieva; Philips Healthcare) and the SENSE Wrist-4 channel coil (Philips Healthcare). Coronal brain images were obtained with rats in the prone position. The MR protocol included T2WI (TR, $4279 \mathrm{~ms}$; TE, $80 \mathrm{~ms}$; flip angle, $90^{\circ} \mathrm{C}$; field of view, $50 \times 50 \mathrm{~mm}$; matrix size, $200 \times 200$; $2 \mathrm{D}$; slice thickness, $1 \mathrm{~mm}$; 3 excitations; resolution, $0.25 \times 0.25 \times 1.0 \mathrm{~mm}), \mathrm{T}_{2}{ }^{*} \mathrm{WI}(\mathrm{TR}, 713 \mathrm{~ms}$; TE, $23 \mathrm{~ms}$; flip angle, $18^{\circ} \mathrm{C}$; field of view, $50 \times 50 \mathrm{~mm}$; matrix size, $200 \times 200$; $2 \mathrm{D}$; slice thickness, $1 \mathrm{~mm}$; 3 excitations; resolution, $0.25 \times 0.25 \times 1.0 \mathrm{~mm})$, and SWI (TR, $31.6 \mathrm{~ms}$;
TE, $44.1 \mathrm{~ms}$; flip angle, $15^{\circ} \mathrm{C}$; field of view, $50 \times 50 \mathrm{~mm}$; matrix size, $128 \times 128$; 3D; slice thickness, $0.5 \mathrm{~mm}$; 3 excitations; resolution, $0.39 \times 0.39 \times 0.5 \mathrm{~mm}$ ).

\subsection{MRI Analysis}

MR images of six PTCI rats intra-arterially infused with SPIO-hMSCs were analyzed using picture archiving and communication system (PACS; Maroview version 5.3; Marotech, Seoul, Korea). A radiologist (B.K.K) assessed successful cerebral infarction induction, occurrence of any abnormal changes due to ICA infusion of SPIO-hMSCs, and distribution of dark regions derived from SPIOhMSCs by comparing the images one by one with the stained slides. The dark regions were graded depending on the amount and pattern of distribution around each cerebral infarct. A strong and continuous distribution surrounding the cerebral infarct was graded as +++. A dark region completely surrounding the cerebral infarct, which was not remarkable or did not completely surround the cerebral infarct with remarkable amounts was graded as ++. A dark region weakly surrounding the cerebral infarct, which had a light band or did not completely surround the cerebral infarct with unremarkable amounts was graded as + . Only marks surrounding the cerebral infarct were graded as +1 - and absence of marks surrounding the cerebral infarct was graded as -. Statistical analysis was performed using Pearson's chi-square test with SPSS version 12.0 (SPSS Inc., Chicago, IL, USA). A P-value less than 0.05 was considered statistically significant.

\subsection{Tissue Extraction and Pathology}

The rats were anesthetized by intramuscular injection of $50 \mathrm{mg} / \mathrm{kg}$ body weight Zoletil 50 (Virbac S.A) and 10 $\mathrm{mg} / \mathrm{kg}$ Rompun (Bayer Korea). The rats were perfused through the heart with $200 \mathrm{~mL}$ of $5 \mathrm{U} / \mathrm{mL}$ heparinized physiological saline followed by $200 \mathrm{~mL}$ of $4 \%$ paraformaldehyde solution. Rat brains were harvested, fixed in $4 \%$ paraformaldehyde solution, and embedded with paraffin. Paraffin block sections with a $5-\mu \mathrm{m}$ thickness were immersed in xylene and ethanol solution for deparaffinization and rehydration. Hematoxylin and eosin (HE) staining was performed. After washing with distilled water, the sections were stained in the hematoxylin and eosin solutions for 8 and $1 \mathrm{~min}$, respectively. Anatomic orientation, ischemic necrosis, inflammation, and hemorrhage were evaluated. Prussian blue staining was performed for the detection of iron from SPIO nanoparticles in hMSCs. Slides were placed in a Coplin jar containing a $1: 1$ mixture of $2 \%$ potassium ferricyanide and $1 \%$ hydrochloric acid for $30 \mathrm{~min}$ at room temperature. They were then rinsed well with distilled water and counterstained with nuclear fast red (Vector Laboratories, Burlingame, CA, USA) for 5 min. Comparing the stained slides one by one with the MR images, SPIO-hMSCs were evaluated with focus on distribution. 
Park S et al.

\section{Results}

Prussian blue staining of SPIO-labeled hMSCs showed that $100 \%$ cells were labeled with SPIO without any cell damage (Figure 1). $\mathrm{T}_{2}$ WI did not detect SPIO-hMSCs in the phantom, even in the highest concentration of 67 SPIOhMSCs $/ \mu \mathrm{L}$ (Figure 2). $\mathrm{T}_{2}{ }^{*} \mathrm{WI}$ showed dark regions in cell lumps of $15 \mu \mathrm{L}$ of $27,40,53$, and 67 SPIO-hMSCs/ $\mu \mathrm{L}$. On SWI, cell lumps of $15 \mu \mathrm{L}$ of 13, 27, 40, 53, and 67 SPIO-hMSCs $/ \mu \mathrm{L}$ showed dark regions. SWI detected a lump with a lower concentration of 13 SPIO-hMSCs $/ \mu \mathrm{L}$ compared with $\mathrm{T}_{2}{ }^{*}$ WI, which detected a lump of 27 SPIO-hMSCs $/ \mu \mathrm{L}$. In all the pulse sequences, lumps not containing cells (only $2 \%$ agarose) and lumps of $15 \mu \mathrm{L}$ of 67 unlabeled hMSCs/ $\mu \mathrm{L}$ did not show any dark regions. The dark regions on SWI were of an exaggerated intensity and were larger than those on $\mathrm{T}_{2}{ }^{*} \mathrm{WI}$ for the same lump.

In normal rat brain MRI, performed an hour after direct SPIO-hMSC implantation, $\mathrm{T}_{2} \mathrm{WI}$ did not show any dark regions (Figure $3 \mathrm{~A}$ ). On $\mathrm{T}_{2}{ }^{*} \mathrm{WI}$ and SWI, $3 \mu \mathrm{L}$ of 333
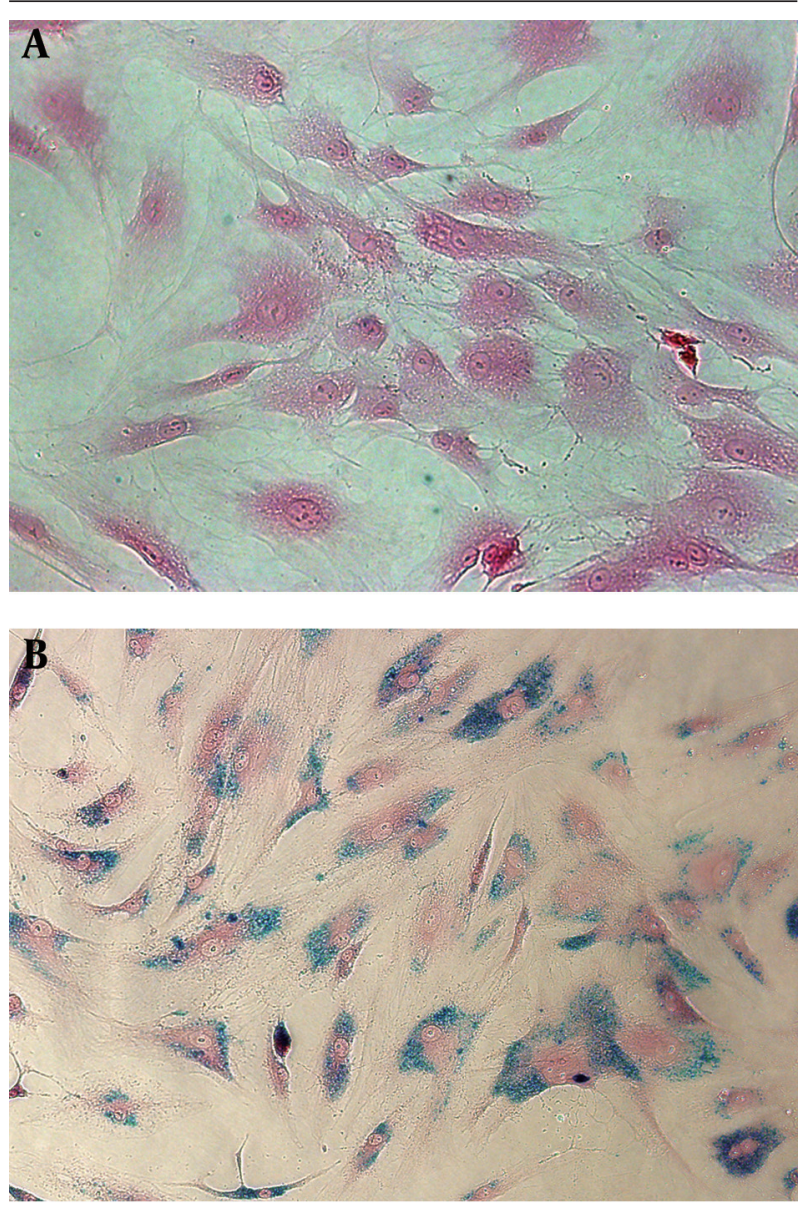

Figure 1. Prussian blue staining of unlabeled human bone marrow. Derived mesenchymal stem cells (hMSCs). A, superparamagnetic iron oxide (SPIO)-labeled hMSCs. B, All hMSCs are sufficiently labeled with SPIO nanoparticles without any cell damage in the medium containing $50 \mu \mathrm{g}$ $\mathrm{Fe} / \mathrm{mL}$ of SPIO nanoparticles and $750 \mathrm{ng} / \mathrm{mL}$ poly L-lysine (magnification, $\times 200)$.

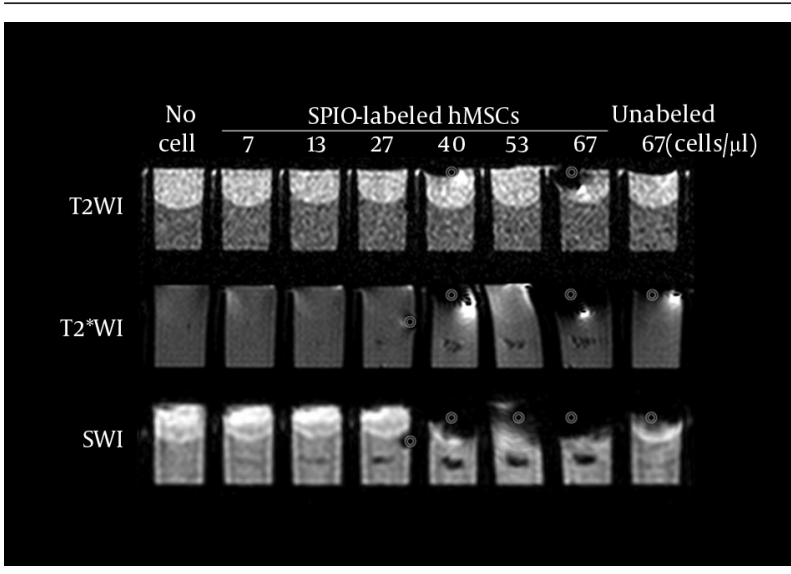

Figure 2. MRI of the phantom with eight wells. Each well has a 15- $\mu \mathrm{L}$ lump of superparamagnetic iron oxide-labeled human bone marrow-derived mesenchymal stem cells (SPIO-hMSCs) in different concentrations: no cells; 7, 13, 27, 40, 53, and 67 SPIO-hMSCs/ $\mu \mathrm{L}$; and 67 unlabeled hMSCs $/ \mu \mathrm{L} . \mathrm{T}_{2}$ weighted imaging $\left(\mathrm{T}_{2} \mathrm{WI}\right)$ does not detect SPIO-hMSCs even in the highest concentration of 67 SPIO-hMSCs $/ \mu \mathrm{L}$. $\mathrm{T}_{2}{ }^{*}$-weighted imaging $\left(\mathrm{T}_{2}{ }^{*} \mathrm{WI}\right)$ shows a dark region for cell lumps in $15 \mu \mathrm{L}$ of $27,40,53$, and 67 SPIO-hMSCs/ $\mu \mathrm{L}$. On susceptibility-weighted imaging (SWI), cell lumps in $15 \mu \mathrm{L}$ of 13, 27, 40, 53 , and 67 SPIO-hMSCs/ $\mu \mathrm{L}$ show dark regions. SWI detects a lump of a lower concentration of 13 SPIO-MSCs $/ \mu \mathrm{L}$ compared with $\mathrm{T}_{2}{ }^{*} \mathrm{WI}$, which detects a concentration of 27 SPIO-MSCs/ $\mu \mathrm{L}$. The dark regions on SWI are more intense and larger in size than those on $\mathrm{T}_{2}{ }^{*} \mathrm{WI}$ for the same lump. The bullseyes indicate air bubble artifacts.

SPIO-hMSCs/ $/ \mathrm{L}$ (right caudate putamen) and $3 \mu \mathrm{L}$ of 167 SPIO-hMSCs/ $/ \mathrm{L}$ (left caudate putamen), respectively, were noted as dark regions on each brain side. The size of the dark region was bigger in 333 SPIO-hMSCs/ $\mu \mathrm{L}$ than in 167 SPIO-hMSCs/ $/ \mathrm{L}$. The dark regions in both caudate putamens were larger and more prominent on SWI than on $\mathrm{T}_{2}{ }^{*} \mathrm{WI}$ (Figure $3 \mathrm{~A}$ ). The implanted cells were confirmed on each side by Prussian blue staining (Figure $3 \mathrm{~B}$ ).

In the normal rat brain MRI performed $24 \mathrm{~h}$ after ICA infusion, one of the three rats (33\%) showed numerous foci of dark regions dispersed throughout the brain on $\mathrm{T}_{2}{ }^{*} \mathrm{WI}$ and SWI (Figure $3 \mathrm{C}$ ), while the other two did not show any dark regions. On Prussian blue staining, these foci were confirmed to be SPIO-hMSCs in the whole brain (Figure $3 \mathrm{D}$ ). The foci were more prominent on SWI than $\mathrm{onT}_{2}{ }^{*} \mathrm{WI}$; however, they were not observed on $\mathrm{T}_{2} \mathrm{WI}$ (Figure $3 \mathrm{C}$ ). The reason for the development of these foci in both cerebral hemispheres of the rats was considered to be a patent circle of Willis.

On MRI, which was obtained $24 \mathrm{~h}$ after ICA infusion with SPIO-hMSCs, focal and oval photothrombotic cerebral infarctions were observed in the right frontoparietal lobe in all six rats with high signal intensity on $\mathrm{T}_{2} \mathrm{WI}, \mathrm{T}_{2}{ }^{*} \mathrm{WI}$, and SWI (Figure $4 \mathrm{~A}$ and $4 \mathrm{C}$ ). Dark regions surrounding the cerebral infarcts were noted, which were most prominent on SWI, followed by $\mathrm{T}_{2}{ }^{*} \mathrm{WI}$ and $\mathrm{T}_{2} \mathrm{WI}$ in all six rats (Table 1) (Figure $4 \mathrm{~A}$ and $4 \mathrm{C}$ ). The trend analysis was statistically significant $(\mathrm{P}=0.002)$. The dark regions occurred because of migration of SPIO-hMSCs through ICA into the surrounding infarction, i.e. engraftment (15). Engraftment was confirmed by Prussian blue staining in all six 
Park S et al.
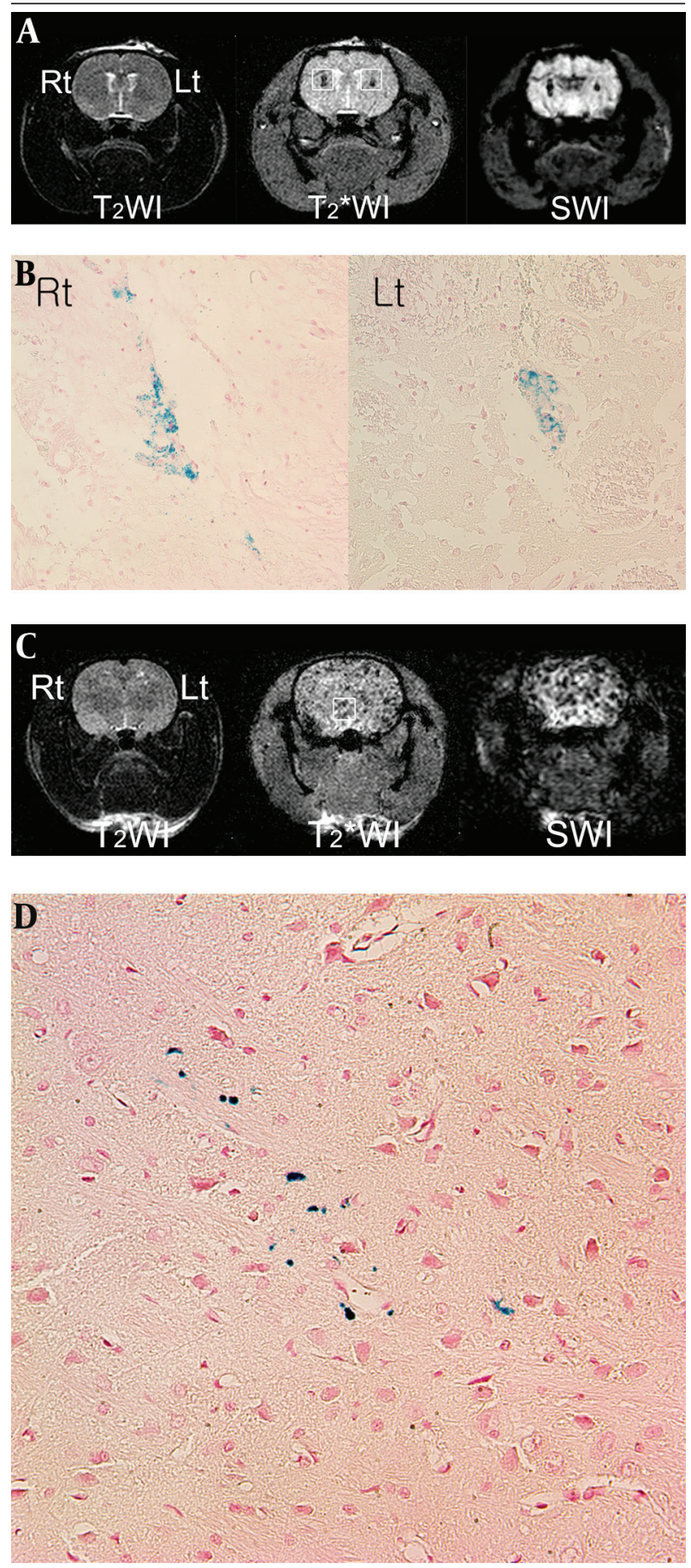

Figure 3. Superparamagnetic iron oxide-labeled human bone marrow. Derived mesenchymal stem cell (SPIO-hMSC) detection using magnetic resonance imaging (MRI) $1 \mathrm{~h}$ after direct implantation (A) and $24 \mathrm{~h}$ after intra-arterial implantation $(\mathrm{C})$ in the normal rat brain $\mathrm{T}_{2}$-weighted imaging (T2WI) does not detect SPIO-hMSCs (A, C). On $\mathrm{T}_{2}{ }^{*}$-weighted imaging $\left(\mathrm{T}_{2}{ }^{*} \mathrm{WI}\right)$ and susceptibility-weighted imaging (SWI), the dark region in the right caudate putamen implanted with $3 \mu \mathrm{L}$ of 333 SPIO-hMSCs/ $\mu \mathrm{L}$ is larger than that in the left caudate putamen implanted with $3 \mu \mathrm{L}$ of 167 SPIOhMSCs $/ \mu \mathrm{L}$ (A, squares). The dark regions are larger and more prominent on SWI than on $\mathrm{T}_{2}{ }^{*} \mathrm{WI}(\mathrm{A})$. On normal rat brain $\mathrm{T}_{2}{ }^{*} \mathrm{WI}$ and SWI, numerous foci of dark regions are dispersed throughout the brain ( $C$, square), probably because the rat has a patent circle of Willis. On Prussian blue staining, the dark regions are confirmed to be SPIO-hMSCs (B, D) (magnification, $\times 400$ )
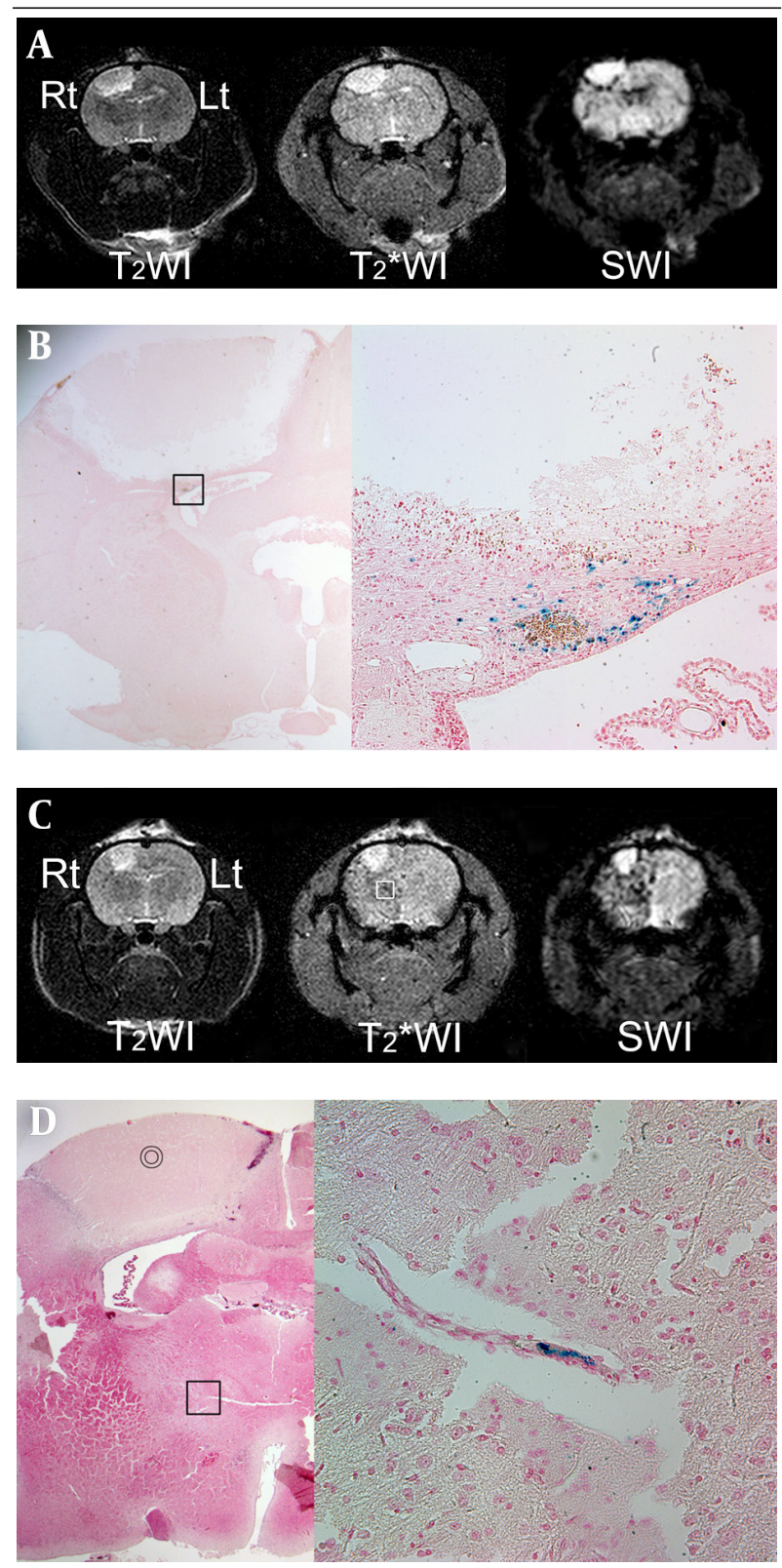

Figure 4. MRI performed $24 \mathrm{~h}$ after intra-arterial superparamagnetic iron oxide-labeled human bone marrow-derived mesenchymal stem cell (SPIO-hMSC) infusion in rats with photothrombotic cerebral infarction. Focal and oval cerebral infarctions are induced in the right frontoparietal lobe, with high signal intensity on $\mathrm{T}_{2}$-weighted imaging $\left(\mathrm{T}_{2} \mathrm{WI}\right), \mathrm{T}_{2}{ }^{*}$ weighted imaging $\left(\mathrm{T}_{2}{ }^{*} \mathrm{WI}\right)$, and susceptibility-weighted imaging (SWI) $(\mathrm{A}$, C). Dark regions surrounding the cerebral infarct are confirmed as engrafted SPIO-hMSCs by Prussian blue staining (magnification, $\times 12.5$ and $\times 400$ ) (B; square). Other foci of dark regions are dispersed in the right hemisphere, particularly on SWI, and they are not remarkable even on $\mathrm{T}_{2}{ }^{*} \mathrm{WI}$ (C, square). The bullseyes indicate cerebral infarction on hematoxylin and eosin staining (magnification, $\times 12.5$ ) (D). The foci of dark regions are identified as SPIO-hMSCs plugging the cerebral artery by Prussian blue staining (magnification, $\times 400$; D; square).

rats (Figure $4 \mathrm{~B}$ ). Meanwhile, foci of dark regions in the ipsilateral cerebral hemisphere in two rats (33\%) were distinctly observed on SWI, faintly observed on $\mathrm{T}_{2}{ }^{*} \mathrm{WI}$, and not observed on $\mathrm{T}_{2} \mathrm{WI}$ (Figure $4 \mathrm{C}$ ). These foci, which developed because of plugging of some small arteries by SPIO-hMSCs, were identified by Prussian blue staining (Figure $4 \mathrm{D}$ ). 
Park S et al.

\begin{tabular}{|c|c|c|c|c|c|}
\hline \multirow{2}{*}{\multicolumn{2}{|c|}{ No. Location of the Infarction }} & \multicolumn{3}{|c|}{ Dark Regions Around the Infarct ${ }^{a, b}$} & \multirow[t]{2}{*}{ Remark } \\
\hline & & $\mathrm{T}_{2} \mathrm{WI}$ & $\mathrm{T}_{2}{ }^{*} \mathrm{WI}$ & SWI & \\
\hline 1 & Rt. frontoparietal & - & + & ++ & \\
\hline 2 & Rt. frontoparietal & - & $+1-$ & +++ & Numerous dark foci in the right hemisphere \\
\hline 3 & Rt. frontoparietal & $+1-$ & + & ++ & \\
\hline 4 & Rt. frontoparietal & $+1-$ & + & ++ & $\begin{array}{l}\text { Numerous dark foci and consequent changes in the right } \\
\text { hemisphere }\end{array}$ \\
\hline 5 & Rt. frontoparietal & - & $+1-$ & ++ & \\
\hline 6 & Rt. frontoparietal & - & $+1-$ & + & \\
\hline
\end{tabular}

\section{Discussion}

This phantom study comparing $\mathrm{T}_{2} \mathrm{WI}, \mathrm{T}_{2}{ }^{*} \mathrm{WI}$, and SWI demonstrated that SWI is the most sensitive in SPIO-hMSC detection. $\mathrm{T}_{2} \mathrm{WI}$ did not detect SPIO-hMSCs in the cell concentration range used in this study. SWI detected a

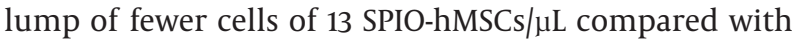
$\mathrm{T}_{2}{ }^{*}$ WI, which detected a lump of 27 SPIO-hMSCs $/ \mu \mathrm{L}$ (Figure 2). It is difficult to compare the sensitivity obtained in this study with that in other studies because of differences in magnet strength (e.g. $4.7 \mathrm{~T}$ vs. 9.4 T) among individual MRI machines, in pulse sequences used for imaging (e.g. spin echo vs. gradient echo; differences in resolution), and in types of cell preparations (e.g. prepared cell number and volume). In a study using 17.6-T MRI with the gradient echo technique, the fewest cells were detected ( $2 \mu \mathrm{L}$ of $50 / \mu \mathrm{L}, 100$ cells) (16). In another phantom study using 9.4-T and 4.7-T MRI with the same phantom and imaging parameters, 9.4-T MRI (gradient echo) was superior in detecting the SPIO-labeled neural stem cells in a concentration of $1 \times 10^{2}$ cells (volume unknown) compared with 4.7-T MRI (gradient echo), which detected cells in a concentration of $5 \times 10^{2}$ cells (volume unknown) (17). They used $2 \%$ gelatin blocks containing SPIO-labeled neural stem cells for the phantom, similar to that used in the present study. The minimal number of cells detected was also similar to that in the present study, in which 15 $\mu \mathrm{L}$ of 27 SPIO-hMSCs/ $\mu \mathrm{L}$ (400 cells) were detected on 3.0-T $\mathrm{T}_{2}{ }^{*}$ WI. Meanwhile, no information is available regarding the minimum cell concentration that can be detected using SWI. In the present study, 3.0-T SWI detected $15 \mu \mathrm{L}$ of 13 SPIO-hMSCs $/ \mu \mathrm{L}$ (200 cells). SWI was used only in one of the several studies performed using MRI for molecular imaging. Cheng et al. first used the SWI pulse sequence for SPIO-hMSCs (12). However, they did not mention the minimal cell number that can be detected using SWI. The size of the dark region derived from SPIO-hMSCs was larger on SWI than on $\mathrm{T}_{2}{ }^{*} \mathrm{WI}$ in the phantom and in the direct and ICA infusion studies of the rat brain (Figures
2 - 4). The size of the dark regions was increased on SWI. Some reports have mentioned the increase in volume on SWI compared with that in the real sample. In the study by Mittal et al. and Babikian et al. SWI was 3-6 times more sensitive than conventional $\mathrm{T}_{2}{ }^{*} \mathrm{WI}$ in detecting the size, number, volume, and distribution of hemorrhagic lesions after cerebral injury $(10,18)$. It may be easy to detect SPIO-hMSCs on SWI because of the increased intensity of dark regions.

At $24 \mathrm{~h}$ after ICA infusion in six rats with photothrombotic cerebral infarction, engrafted SPIO-hMSCs were detected around the cerebral infarction $(6 / 6,100 \%)$ on MRI (Figure 4). ICA infusion is very effective in delivering stem cells to the lesion, particularly in the early phase after infusion $(15,19,20) . T_{2}$ WI did not detect SPIO-hMSCs observed as dark regions in other sequences. The surrounding dark regions were more prominent on SWI than on $\mathrm{T}_{2}{ }^{*}$ WI. Meanwhile, SPIO-hMSCs were also detected and distributed in the whole ipsilateral normal parenchyma $(2 / 6,33 \%)$ (Figure 4$)(15,21)$ probably because of plugging of end arteries in the cerebrum that led to infarction (Figure $3 \mathrm{C}$ and $4 \mathrm{C}$ ). The dark regions caused by plugging of end arteries were also more distinct on SWI than on $\mathrm{T}_{2}{ }^{*}$ WI. However, plugging of the end artery is suspected to be developed only in a small animal study because of the relatively small cerebral artery caliber. In humans, plugging of end arteries cannot be suspected because of the large cerebral artery caliber and some other techniques that prevent dispersed cell aggregation. The cells infused into one side of the brain are distributed to the contralateral side (Figure $3 \mathrm{C}$ ) probably because of a patent circle of Willis. This phenomenon is also not critical to humans because small-caliber arteries distal to the circle of Willis can be superselected.

SWI has drawbacks, such as artifacts, which are not frequent with other MRI pulse sequences (Figures 2 - 4). SWI can detect non-uniformity of local magnetic fields 
Park S et al.

caused by paramagnetic and diamagnetic tissues (11, 22, 23). Paramagnetic materials always demonstrate low signal intensity on magnitude and phase images, while diamagnetic materials demonstrate high signal intensity on phase images and low signal intensity on magnitude images (24). Therefore, when interpreting SWI findings, paramagnetic materials that can result in dark signal artifacts, such as deoxygenated venous blood, hemorrhage, iron, and air, should be ruled out $(10,11)$.

This study has limitations. First, because of the indirect detection of cells through the SPIO effect on proton relaxation, it was difficult to absolutely quantify the cell concentration (25). Second, it was difficult to discriminate SPIO-labeled cells in areas of hemorrhage and traumatic injury because of proton dephasing effects of methemoglobin, ferritin, and hemosiderin, particularly at higher fields. There is a possibility of occasional misinterpretation of isolated dark regions because of differences in magnetic susceptibility around blood vessels and airtissue interfaces (i.e. stomach and gastrointestinal tract). Third, in the in vivo study, there was no exact correlation between MRI and the actual cell number. Researchers only know the number of infused cells and not the number of imaged cells. Fourth, the number of rats included in this study was too small. Therefore, a further study with more rats is warranted. For practical applications, the labeling of cells with SPIO nanoparticles and MRI are expected to effectively track the cells in the human (26). Because the resolution of MR images is much lower in humans than in small animals, the most sensitive pulse sequence is undoubtedly needed. Based on this animal study, it will make human trial successful with SWI pulse sequence.

In conclusion, SWI is the most sensitive in the detection of SPIO-hMSCs compared with $\mathrm{T}_{2}{ }^{*} \mathrm{WI}$ and $\mathrm{T}_{2} \mathrm{WI}$, with the dark regions representing SPIO-hMSCs being more prominent on SWI than on the other two pulse sequences.

\section{Acknowledgements}

This research was supported by the Biomedical Science Department of Medicine Research Scholarship Grants, Chung-Ang University in 2014.

\section{Authors' Contributions}

Study concept and design: Serah Park, Byung Kook Kwak, and Jisung Jung. Analysis and interpretation of data: Serah Park, Byung Kook Kwak, and Jisung Jung. Drafting of the manuscript: Serah Park. Critical revision of the manuscript for important intellectual content: Serah Park, Byung Kook Kwak, and Jisung Jung. Statistical analysis: Byung Kook Kwak, and Jisung Jung.

\section{References}

1. Long CM, Bulte JW. In vivo tracking of cellular therapeutics using magnetic resonance imaging. Expert Opin Biol Ther. 2009;9(3):293-306.
2. Bulte JW. In vivo MRI cell tracking: clinical studies. AJR Am J Roentgenol. 2009;193(2):314-25.

3. Bulte JW, Kraitchman DL. Iron oxide MR contrast agents for molecular and cellular imaging. NMR Biomed. 2004;17(7):484-99.

4. Mohammadi-Nejad AR, Hossein-Zadeh GA, Soltanian-Zadeh H. Quantitative evaluation of optimal imaging parameters for single-cell detection in MRI using simulation. Magn Reson Imaging. 2010;28(3):408-17.

5. Hu SL, Lu PG, Zhang LJ, Li F, Chen Z, Wu N, et al. In vivo magnetic resonance imaging tracking of SPIO-labeled human umbilical cord mesenchymal stem cells. J Cell Biochem. 2012;113(3):1005-12.

6. Reddy AM, Kwak BK, Shim HJ, Ahn C, Cho SH, Kim BJ, et al. Functional characterization of mesenchymal stem cells labeled with a novel PVP-coated superparamagnetic iron oxide. Contrast Media Mol Imaging. 2009;4(3):118-26.

7. Wang L, Deng J, Wang J, Xiang B, Yang T, Gruwel M, et al. Superparamagnetic iron oxide does not affect the viability and function of adipose-derived stem cells, and superparamagnetic iron oxide-enhanced magnetic resonance imaging identifies viable cells. Magn Reson Imaging. 2009;27(1):108-19.

8. Liu W, Frank JA. Detection and quantification of magnetically labeled cells by cellular MRI. Eur J Radiol. 2009;70(2):258-64.

9. Rogers WJ, Meyer $\mathrm{CH}$, Kramer CM. Technology insight: in vivo cell tracking by use of MRI. Nat Clin Pract Cardiovasc Med. 2006;3(10):554-62.

10. Mittal S, Wu Z, Neelavalli J, Haacke EM. Susceptibility-weighted imaging: technical aspects and clinical applications, part 2. AJNR Am J Neuroradiol. 2009;30(2):232-52.

11. Haacke EM, Mittal S, Wu Z, Neelavalli J, Cheng YC. Susceptibilityweighted imaging: technical aspects and clinical applications, part 1. AJNR Am J Neuroradiol. 2009;30(1):19-30.

12. Cheng JL, Yang YJ, Li HL, Wang J, Wang MH, Zhang Y. In vivo tracing of superparamagnetic iron oxide-labeled bone marrow mesenchymal stem cells transplanted for traumatic brain injury by susceptibility weighted imaging in a rat model. Chin J Traumatol. 2010;13(3):173-7.

13. Jisung J, Kwak BK, Reddy AM, Ha BC, Shim HJ, Byun JS, et al. Characterization of Photothrombotic Cerebral Infarction Model At Sensorimotor Area of Functional Map in Rat.J Neurol Sci (Turkish). 2013;30(4):617-28.

14. Kuroiwa T, Xi G, Hua Y, Nagaraja TN, Fenstermacher JD, Keep RF. Brain edema and blood-brain barrier opening after photothrombotic ischemia in rat. Acta Neurochir Suppl. 2013;118:11-5.

15. Byun JS, Kwak BK, Kim JK, Jung J, Ha BC, Park S. Engraftment of human mesenchymal stem cells in a rat photothrombotic cerebral infarction model : comparison of intra-arterial and intravenous infusion using MRI and histological analysis. J Korean Neurosurg Soc. 2013;54(6):467-76.

16. Stroh A, Faber C, Neuberger T, Lorenz P, Sieland K, Jakob PM, et al. In vivo detection limits of magnetically labeled embryonic stem cells in the rat brain using high-field (17.6 T) magnetic resonance imaging. Neuroimage. 2005;24(3):635-45.

17. Magnitsky S, Watson DJ, Walton RM, Pickup S, Bulte JW, Wolfe JH, et al. In vivo and ex vivo MRI detection of localized and disseminated neural stem cell grafts in the mouse brain. Neuroimage. 2005;26(3):744-54.

18. Babikian T, Freier MC, Tong KA, Nickerson JP, Wall CJ, Holshouser BA, et al. Susceptibility weighted imaging: neuropsychologic outcome and pediatric head injury. Pediatr Neurol. 2005;33(3):184-94.

19. Walczak P, Zhang J, Gilad AA, Kedziorek DA, Ruiz-Cabello J, Young RG, et al. Dual-modality monitoring of targeted intraarterial delivery of mesenchymal stem cells after transient ischemia. Stroke. 2008;39(5):1569-74.

20. Shen LH, Li Y, Chen J, Zhang J, Vanguri P, Borneman J, et al. Intracarotid transplantation of bone marrow stromal cells increases axon-myelin remodeling after stroke. Neuroscience. 2006;137(2):393-9.

21. Li L, Jiang Q, Ding G, Zhang L, Zhang ZG, Li Q, et al. Effects of administration route on migration and distribution of neural progenitor cells transplanted into rats with focal cerebral ischemia, an MRI study. J Cereb Blood Flow Metab. 2010;30(3):653-62.

22. Deistung A, Dittrich E, Sedlacik J, Rauscher A, Reichenbach JR. 
ToF-SWI: simultaneous time of flight and fully flow compensated susceptibility weighted imaging. J Magn Reson Imaging. 2009;29(6):1478-84.

23. Chavhan GB, Babyn PS, Thomas B, Shroff MM, Haacke EM. Principles, techniques, and applications of T2*-based MR imaging and its special applications. Radiographics. 2009;29(5):1433-49.

24. Zulfiqar M, Dumrongpisutikul N, Intrapiromkul J, Yousem DM Detection of intratumoral calcification in oligodendrogliomas by susceptibility-weighted MR imaging. AJNR Am J Neuroradiol.
2012;33(5):858-64.

25. Bulte JW, Walczak P, Gleich B, Weizenecker J, Markov DE, Aerts HC, et al. MPI Cell Tracking: What Can We Learn from MRI? Proc Soc Photo Opt Instrum Eng. 2011;7965:79650z.

26. Karussis D, Karageorgiou C, Vaknin-Dembinsky A, Gowda-Kurkalli B, Gomori JM, Kassis I, et al. Safety and immunological effects of mesenchymal stem cell transplantation in patients with multiple sclerosis and amyotrophic lateral sclerosis. Arch Neurol. 2010;67(10):1187-94. 